\title{
Susan Blackmore Responds
}

To the Editor:

Leon Rhodes believes "that the large number of OBEs of great variety are telling us something, and we should be paying attention." I couldn't agree more.

But what comes of our attention is entirely different. Rhodes argues that God has control of our lives and can give the OBE as a glimpse of an afterlife-while not compelling us to believe in it. He further seems to accept that something leaves the body and survives after the death of that body. He awaits death with confidence that a further life follows.

I prefer to use my attention in two quite different ways: first by having OBEs and practicing altered states of consciousness, and sec- 
ond by keeping on asking questions when explanations seem inadequate. In this way experience and explanation work on each other.

I would like to set the OBE in the context of the many experiences that occur during personal development, during training in meditation, when taking drugs (especially hallucinogens), and when facing death or other life crises. For those of us who seek explanations (and Rhodes is clearly one) there are generally three kinds.

First there are the occult or pseudo-scientific explanations. These are characterized by ad hoc multiplication of "new energies," "vibrations" or "forces unknown to science." While couched in apparently scientific terms they cannot be made to yield predictions and do little or no scientific work. Their great appeal is that they seem to account for the phenomenology of the experiences.

To someone who has had an OBE the idea of the astral body may make a lot of sense and give reassurance. However, the astral body is, as I have tried to show, a vacuous concept (Blackmore 1982). Rhodes points out that "The DNA helix became a useful model without being seen or weighed." Indeed it did. And that is precisely what the astral body fails to do. It is not a useful model. It explains nothing (e.g., why the OB world looks the way it does, why OBEs occur when they do, why one looks from above and not from across the room on the floor) and predicts nothing. I used the examples of weighing and seeing as possible predictions that have failed the test of experiment. For these reasons, and not without a little sadness, I reject the whole concept of astral projection.

The second type of explanation is the skeptical dismissive type. This is just as useless. In the case of OBEs one might say "they are just hallucinations," "just imagination," or, for those convinced of perception at a distance, "imagination plus ESP." The advantage of such "theories" is that no great revision of science is required. However no scientific work is done here either. Such theories cannot explain the phenomenology of the OBE and their predictions are limited.

Considering these all too common approaches makes it clear what the criteria should be for a really useful theory of the OBE. It should first account for the phenomenology (explain why the OBE is like it is and why it comes about, and make good sense to experiencers); second it should build on scientific understanding rather than rejecting it; and third it should provide helpful predictions.

I have proposed that the OBE occurs when a person's normal sensebased "model of reality" breaks down and a bird's eye view constructed from memory and imagination takes over as "real" (Blackmore 1984). I do not claim that this fulfills all the criteria of a good theory in one go. 
Nevertheless, it does account for why the OBE seems so real, why the OB world has the features of "cognitive maps," why experiments searching for an astral body or astral vision have failed, and what conditions can initiate and end an OBE. It has also led to predictions, such as that people with good spatial imagery skills and those who are better able to switch viewpoints in imagery should be more likely to report OBEs. These predictions have been confirmed (Blackmore 1987; Irwin 1986). It is also competing with other related theories, such as Irwin's "synaesthetic model of the OBE" (Irwin 1985). In other words, we can make progress with such theories.

The same three approaches can be applied, for example, to the tunnel experience. It is not helpful to compare the tunnel to the birth canal or make it a path to another life (Sagan 1977; Blackmore 1988). It is equally pointless to call it "just imagination." However, recent theories that explain how it arises from the structure of the visual cortex make a genuine contribution to our understanding of NDEs (Blackmore 1988; Cowan 1982).

Experiences of oneness, cosmic consciousness, self-transcendence, and emptiness may look harder to tackle, but the same principles apply.

I am acutely aware that some readers will take this approach as some kind of denial of the validity of the OBE, and indeed of all sorts of experiences that they find spiritually or personally important. No such denial is intended, nor does it follow from what I have said.

Seeing the OBE as a purely psychological phenomenon, as an "illusion of reality," puts it in a most interesting perspective. There are many experiences that contribute to a person dropping the usual illusion that we are independent selves inhabiting bodies and separate from the world around us. The OBE can be one such experience. It can make the physical body seem unimportant, one's daily desires and intrigues trivial, and a world other than the sensory world seem "real." However, it is a very limited step. The usual body is replaced by a replica, and the world around just seen from a different viewpoint. For some it can be a stepping stone, however. The replica can be dropped, the imagined world allowed to dissolve, and progress to less restricted states made.

These further steps are easier if you drop the astral projection notion, and they are helped by psychology's insight that the self and world are constructions of an information processing system. If OBEs "are telling us something" I think it is how strong is our tendency to hang onto our constructions of a self and its world.

This reminds me that, in many spiritual traditions, trainees are 
advised to ignore such experiences if they wish to progress. A fruitful science of personal development will make the reason for this injunction quite obvious (Blackmore, in press). Although such work is in its infancy, it is certainly beginning (Wilber, Engler, \& Brown, 1986).

The analogy with the three kinds of explanation should now be clear. The first is just like the clinging to that replica body. It replaces one world of bodies and objects with another, one self with another. The second also blocks further questioning by denying that the experience is interesting. Only the third (in its widest sense, not any one theory) really "pays attention." The person who tries this approach does not rest with easy "answers" and can only go on experiencing and questioning. In this way personal experience and science require the same skills, not to rest content with vacuous explanations and to keep on facing up to the phenomena.

And what is the point of all this? Unlike Rhodes, I do not assume that life has a purpose nor any goal. I do not await death with any certainty of an afterlife. Indeed, I rather imagine that with practice I might die before my physical body rather than afterwards.

\section{References}

Blackmore, S. J. (1982). Beyond the body. London, England: Heinemann.

Blackmore, S. J. (1984). A psychological theory of the OBE. Journal of Parapsychology, 48, 201-218.

Blackmore, S. J. (1987). Where am I? Perspectives in imagery and the out-of-body experience. Journal of Mental Imagery, 11(2), 53-66.

Blackmore, S. J. (1988). Visions of the dying brain. New Scientist, 1611, 43-46.

Blackmore, S. J. (in press). Experiences along the path. In The New Age: A Skeptical Critique. Buffalo, NY: Prometheus.

Cowan, J. D. (1982). Spontaneous symmetry breaking in large scale nervous activity. International Journal of Quantum Chemistry, 22, 1059-1082.

Irwin, H. J. (1985). Flight of mind: A psychological study of the out-of-body experience. Metuchen, NJ: Scarecrow Press.

Irwin, H. J. (1986). Perceptual perspectives of visual imagery in OBEs, dreams and reminiscence. Journal of the Society for Psychical Research, 53, 210-217.

Sagan, C. (1977). Broca's brain. New York, NY: Random House.

Wilber, K., Engler, J., and Brown, D. P. (Eds.). (1986). Transformations of consciousness. Boston, MA: Shambhala.

Susan Blackmore

Brain and Perception Laboratory

University of Bristol

Bristol BS8 1TD

England 